few colour plates and their quality is patchy (the spotty egg photos are particularly disappointing given their importance in the book). The volume is written with both the professional scientist and interested amateur in mind, and would make an enjoyable read for both. Generally, this is a remarkable book, which describes brood parasitism and its evolution clearly and comprehensively, and sets the stage for the next round of exciting discoveries.

Robert C. Fleischer is at the National Zoological Park, Smithsonian Institution, Washington DC 20008, USA.

\section{Time to deal with the legacy of secrecy}

\section{Undue Risk: Secret State}

Experiments on Humans

by Jonathan D. Moreno

W. H. Freeman: 2000.320 pp. \$24.95, £14.95

\section{Arthur C. Upton}

This revealing account of governmentsponsored experiments on human subjects benefits from Jonathan Moreno's experience as a senior member of President Bill Clinton's Advisory Committee on Human Radiation Experiments. Although Moreno makes no attempt to document such experiments comprehensively, the many examples he describes comprise a historically significant and illuminating series. They include research by Walter Reed and the Yellow Fever Commission on human volunteers at the beginning of last century, the Tuskegee syphilis study, experiments to find ways of protecting soldiers against mustard gas in the Second World War, and against chemical and biological weapons in the Gulf War, and other experiments to determine the effects of penicillin, nitrogen mustard, antimalarials, mescaline, plutonium and whole-body ionizing radiation.

The subjects in such research were patients, retarded children, volunteers, servicemen and prisoners, many of them recruited without informed consent, some unwittingly. For example, Moreno discusses the US government's failure to inform uranium miners, servicemen and members of the public about the risks of exposure to radiation when the United States was developing and testing atomic weapons. He also cites how NASA recruited Nazi experts to its space programme despite knowing about the atrocities perpetrated by the Nazis, and their horrific experiments on concentrationcamp prisoners. Other egregious research discussed includes that conducted by Shiro Ishii on Chinese and Russian victims in Manchuria and by the Iraqi government on Kurds and other populations in Iraq.
In recounting details of these statesponsored experiments, Moreno gives penetrating insights into the circumstances surrounding them. He also highlights the personalities involved, the issues that were at stake, and the personal, professional and public attitudes of the time. In the process, he chronicles the need for, and gradual evolution and acceptance of, an ethical framework for research on humans. Such a framework should embody the principles of voluntary participation and informed consent, as exemplified in the Nuremberg Code.

Moreno says at the end of the book that he believes experiments on humans will continue to be necessary, not only for the premarket testing of new pharmaceuticals and other products, but also to protect populations from the threat of attack by atomic, chemical and biological weapons. He recommends that, in order to ensure that such experiments meet ethical standards of openness and informed consent, the international community should set up a "research ethics court".

In going behind the scenes to describe the struggles with the ethics of human experimentation among government officials concerned with national security, Moreno shows vividly how a policy of secrecy that seemed

\section{New in paperback}

\section{Evolving Brains}

by John Allman

Scientific American Library, \$22.95

"It is quite remarkable in presenting a radically novel picture of the evolution of the brain...

Evolving Brains is a masterpiece of synthetic presentation and evocative interpretation." Bob Martin, Nature 399, 426-427 (1997)

The Generation of Diversity: Clonal Selection Theory and the Rise of Molecular Immunology

by Alfred I. Tauber \& Scott H. Podolsky

Harvard University Press, \$35.00, £21.95

"A dense and exhaustive scholarly treatise about the history of GOD. They explore the intellectual setting in which the Tonegawa experiment was performed by reviewing original literature and interviewing the major actors in the drama. This is not reading material for lay people, but everyone interested in the history of immunology and genetics should read this book." Fred S. Rosen, Nature 395, 235-236 (1998)

\section{Burnet - A Life}

by Christopher Sexton

Oxford University Press, $£ 17.95$

"I would have like to have seen a greater emphasis on the descriptions and implications of self-tolerance and clonal selection at the expense of detailing Burnet's more trivial encounters with justifiable to those directly involved proved ultimately to be corrosive to democracy and to seriously violate human rights. Looking at the lessons to be learnt from this, he argues persuasively that although research on humans for military and medical purposes will probably continue indefinitely, this should be only for defensive rather than offensive purposes, should meet ethical standards of informed consent, and should expose none of its participants to undue risks. Moreno's call for an ethical review process to ensure that investigators consistently meet such standards merits the serious attention of citizens and governments everywhere.

Undue Risk deals in a balanced, scholarly way with the issues involved, documenting the sources of information with appropriate references. Although the book was written for a general readership, it has a timely and important message, and should be relevant to all those concerned with military preparedness, defence and the ethics of human experimentation.

Arthur C. Upton is in the Department of Environmental and Community Medicine, University of Medicine and Dentistry of New Jersey-Robert Wood Johnson Medical School, 317 George Street, New Brunswick, New Jersey 08901, USA royalty. Nevertheless, the book brings alive the nature of the scientific quest and shows the excitement that a man of Burnet's genius can bring to the evolution of broad ideas, as well as how these ideas can spark off whole generations of scientists. Would that we could all have such an impact." I. M. Roitt, Nature 355, 779-780 (1992) - from the review of The Seeds of Time: The Life of Sir Macfarlane Burnet, the title under which the book was originally published in 1992.

The Nemesis Affair: A Story of the Death of Dinosaurs and the Ways of Science

by David M. Raup

W. W. Norton, £8.95

Avatars of the Word: From Papyrus to Cyberspace

by James J. O'Donnell

Harvard University Press, £9.50

The Bone Lady: Life As A Forensic Anthropologist

by Mary H. Manhein

Penguin Books, £11.95

Is the Temperature Rising?

The Uncertain Science of Global Warming

by S. George Philander

Princeton University Press, $\$ 16.95, £ 10.50$ 